\title{
Voltage Enhancement on DFIG Based Wind Farm Terminal During Grid Faults
}

\author{
Phan Dinh Chung \\ The University of Danang - University of Science and Technology \\ Danang, Vietnam \\ pdchung@dut.udn.vn
}

\begin{abstract}
This paper proposes a method of retaining high enough voltage on the terminal of DFIG wind turbines during a fault interval on the connected grid. This method is developed by the ideal of dynamic voltage restorer equipment and was applied to a wind turbines group. The DC-link and the grid side converter of the first DFIG wind turbine in this group are utilized to support the other wind turbines. The converter is connected to a transformer, which is in series with the wind turbine group and the connected line, during an external fault. At the DC-link of the back-to-back converter of each DFIG wind turbine, a DC chopper is equipped to dissipate excessive active power during the fault interval. Moreover, the controllers of all wind turbines are modified to support all wind turbines in the group. The method is verified by MATLAB/Simulink. Simulation results implied that the proposed method can retain a high enough voltage on the terminal of DFIG while preventing overcurrent on the rotor side.
\end{abstract}

Keywords-DFIG; DVR; fault-ride-through capability; voltage enhancement; wind turbine

\section{INTRODUCTION}

Wind industry develops rapidly in many countries and many wind farms have been deployed successfully. According to [1], China owns the world's highest installed capacity with about $211 \mathrm{GW}(35.74 \%)$, followed by USA and Germany with about $96 \mathrm{GW}(16.34 \%)$ and $60 \mathrm{GW}(10.07 \%)$ respectively. In general, there are three kinds of generators used widely in wind turbines. These are: squirrel cage induction generator (SCIG), doubly-fed induction generator (DFIG) and permanent magnetic synchronous generator (PMSG) [2]. DFIG and PMSG wind turbines are more popular as they offer better control abilities [3]. However, in case of a voltage sag in the grid, the DFIG wind turbine's response differs from the PMSG's. In PMSG, the generator is isolated from the connected grid using a frequency converter and hence, the voltage sag does not have serious negative impact on generator $[4,5]$. In contrast, the stator side of the DFIG wind turbine is directly connected to the external grid and hence, a voltage sag on the external grid has a serious negative impact on the generator, causing overcurrent in the rotor winding [6]. Therefore, supporting DFIG wind turbine during a voltage sag becomes a critical issue. Many methods have been proposed that support DFIG wind turbines during a voltage sag [7-14]. Conventionally, a crowbar was suggested to avoid the overcurrent in the rotor side [7, 8]. However, when the crowbar in the rotor side of DFIG is activated, DFIG becomes an SCIG wind turbine consuming a significant amount of reactive power from the external grid, reducing the generator's terminal voltage. Another suggestion was the installation of a chopper at the DC-link of the back-to-back converter [9], which still allows overvoltage on the DC-link and damages the converters of the DFIG wind turbine. A combination of crowbar and chopper was studied in [10], but the problem of reactive power requirement for DFIG has not been solved yet. Series dynamic braking resistors (SDBR) were suggested to overcome the drawback of using crowbar and chopper, because a high enough voltage can remain at the generator terminal [11], but it requires two SDBR to be installed at both stator and rotor side. Fault current limiter (FCL) [12] was used to limit fault current and improve the rotor side converter (RSC) controllability, but it increased cost significantly. FACTS devices were also introduced to enhance the DFIG's fault-ride through (FRT) ability $[13,14]$. The use of a static VAR compensation (SVC) or STATCOM to support the DFIG wind turbine's FRT capability could not obtain high efficiency because of low voltage at its terminal during an external short-circuit. Dynamic voltage restorer (DVR) can eliminate transience in the windings of DFIG and restore voltage quickly, and hence the back-to-back-converter's controllability during an external fault becomes as good as in normal operation. However, DVR is quite expensive.

In order to overcome the cost of DVR, many improvements have been proposed. In [15], DVR was employed but authors utilized the DC-link of DFIG wind turbine to replace the DCsource of DVR, saving investment cost. In [16], authors utilized both the DC-link and the grid side converter (GSC) of the DFIG wind turbine to operate as a DVR, replacing both the DC-source and the converter in DVR. While these improvements can save investment cost, the use of these configurations in a wind farm brings some disadvantages. Firstly, it is quite expensive as DVR is used at each wind turbine. Secondly a lot of space is required in each wind turbine for the installation of the converter, the series transformer and auxiliary equipment, requiring a bigger nacelle and stronger foundation. This paper considers the use of a DVR to support the FRT capability of a wind turbine group, utilizing the DC link and the grid side converter of the first DFIG wind turbine in the group to support the others. This converter is connected 
to a series transformer between the wind turbine group and the connected line. Moreover, a chopper is installed at the DC-link of the back-to-back converter of each DFIG wind turbine, to consume active power during fault periods. The converter's controller at each DFIG wind turbine is modified to minimize active power supply to the series transformer. This idea is verified by simulation in MATLAB/Simulink and the simulation results are compared to the conventional scheme that uses a crowbar and a chopper at each wind turbine.

\section{PROPOSAL OF FRT METHOD FOR WIND TURBINE GROUP}

We suppose that a wind farm consists of several groups of wind turbines. Each group consists of 4 DFIG-wind turbines and each wind turbine is connected to collector line through a step-up transformer. To support the FRT capability of all wind turbines in a group during external fault interval, a DVR is used as shown in Figure 1. The DC-link and GSC of the first DFIG wind turbine replaces the DC-source and the converter of DVR respectively. During normal operation, GSC of the first wind turbine is connected to the collector line through the low-side of the step-up transformer by switching the SW1 switch to pole A and closing SW2. When an external fault is detected, the SW1 switch is automatically switched to pole B so that the grid side converter is connected to the series transformer and the SW2 switch is opened. In this case, the DC-link, the GSC of the first wind turbine and the series transformer play the role of DVR, injecting voltage, so that a high enough voltage can remain on the collector line.

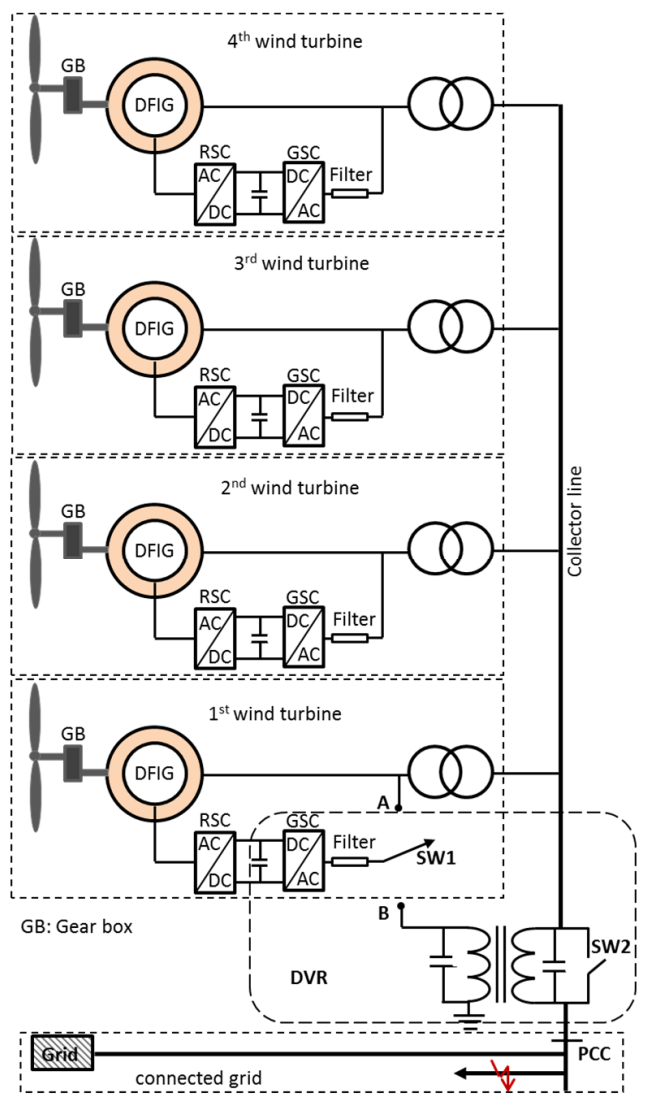

Fig. 1. Configuration of a wind turbine group

\section{DFIG WIND TURBINE}

A DFIG wind turbine consists of a variable speed turbine, a generator and a gearbox $[17,18]$. The main objective of turbine is to convert wind power to mechanical power on its shaft. The relationship between mechanical power, $P_{m}$, and rotor speed, $\omega_{r}$, is described as [19]:

$$
P_{m}=\frac{1}{2} \rho \pi R^{5} \frac{C_{p}(\lambda, \beta)}{\lambda^{3}} \omega_{r}^{3},
$$

where $\rho, R, C_{p}, \lambda$, and $\beta$ are air density, blade's length, power coefficient, tip-speed ratio, and pitch angle respectively. The relationship between $\lambda, \omega_{r}$, and wind speed $V_{w}$ is:

$$
\lambda=\frac{R \omega_{r}}{V_{w}}(2)
$$

When $\beta$ is constant, $C_{p}(\lambda)$ has a unique maximum point with respect to $\lambda$. This means that $P_{m}$ has a unique maximum point. The locus of maximum $P_{\max }$ versus $\omega_{r}$ is described as[20]:

$$
P_{\max }=k \omega_{r}^{3}
$$

where $k=\frac{1}{2} \rho \pi R^{5} \frac{C_{p}\left(\lambda_{o p t}, \beta\right)}{\lambda_{o p t}^{3}}$ and $\lambda_{\text {opt }}$ is the optimal value of $\lambda$. The mechanical power on the shaft is converted to electrical power output in the stator and rotor winding of DFIG. In $d q$ frame, where $d$ axis is aligned with the stator flux vector, DFIG can be described as [20]:

$$
\begin{gathered}
\mathbf{v}_{r d q}=R_{r} \mathbf{i}_{r d q}+\sigma \frac{d \mathbf{i}_{r d q}}{d t}+s \boldsymbol{\Phi} \frac{L_{m}}{L_{s}}\left[\begin{array}{c}
V_{s} \\
0
\end{array}\right]+\omega_{s} s \sigma \boldsymbol{\Phi} \mathbf{i}_{r d q} \\
\mathbf{v}_{r d q}=\left[\begin{array}{c}
v_{r d} \\
v_{r q}
\end{array}\right] ; \quad \mathbf{i}_{r d q}=\left[\begin{array}{c}
i_{r d} \\
i_{r q}
\end{array}\right] \\
\sigma=L_{r}-\frac{L_{m}^{2}}{L_{s}} ; \quad \boldsymbol{\Phi}=\left[\begin{array}{cc}
0 & -1 \\
1 & 0
\end{array}\right] \\
P_{s}=-\frac{L_{m}}{L_{s}} V_{s} i_{r q} ; \quad P_{r}=\frac{L_{m}}{L_{s}} s V_{s} i_{r q}
\end{gathered}
$$

where, $v, i, P$ and $s$ are corresponding to voltage, current, active power and slip of DFIG, $R$ and $L$ correspond to resistance and inductance, $r, s, m, d$ and $q$ stand for rotor side, stator side, multal, $d$ axis, and $q$ axis respectively, while $V_{s}$ is the magnitude voltage of stator winding. Motion equation in DFIG wind turbine can be described as:

$$
\frac{J}{2} \frac{d \omega_{r}^{2}}{d t}=P_{m}-(1-s) P_{s}
$$

where $J$ is the inertia constant of the DFIG wind turbine. The DFIG's grid side converter is connected to the connected grid through a filter, described in the $d q$ frame as [21]:

$$
\begin{gathered}
\mathbf{v}_{g d q}=R_{f} \mathbf{i}_{g d q}+L_{f} \frac{d \mathbf{i}_{g d q}}{d t}+\mathbf{v}_{c d q}+\omega_{s} L_{f} \boldsymbol{\Phi} \mathbf{i}_{g d q} \\
\mathbf{v}_{g d q}=\left[\begin{array}{l}
v_{g d} \\
v_{g q}
\end{array}\right] ; \mathbf{i}_{g d q}=\left[\begin{array}{l}
i_{g d} \\
i_{g q}
\end{array}\right] ; \mathbf{v}_{c d q}=\left[\begin{array}{l}
v_{c d} \\
v_{c q}
\end{array}\right] \\
P_{g}=v_{g d} i_{g d}+v_{g q} i_{g q}
\end{gathered}
$$

where $v, i, P$ and $s$ are corresponding to voltage, current, active power and slip of DFIG and $f, g$ and $c$ stand for filter, grid side and converter, respectively. The DC link in the back-to-back converter is described by: 


$$
\frac{c}{2} \frac{d V_{d c}^{2}}{d t}=P_{r}-P_{g}
$$

where, $C$ is capacitance and $V_{d c}$ is DC voltage on the DC link.

\section{CONTROLER MODIFICATION OF CONVERTERS}

The ability of active power generation depends on the stator voltage and hence if normal voltage can be retained on the terminal of the generator during an external fault interval, the generator can generate active power as in normal operation. However, if a voltage sag happens at the point of common coupling (PCC), active power cannot be supplied to the connected grid. Hence, the controllers of wind turbines should be modified in order to ensure the stable operation of wind turbine during and after an external fault.

\section{A. The First Wind Turbine in the Group}

During normal operation, the wind turbine's rotor side converter adjusts rotor speed to obtain the maximum power point tracking of the wind turbine and retain constant voltage at the stator winding terminal, while the grid side converter is controlled to keep DC voltage at the rated value and $q$ component grid side current at zero. During an external fault interval, GSC is connected to the series transformer so as to inject voltage into the collector line. Hence, both the RSC controller and the GSC controller should be modified. The RSC controller aims to control DC and the stator's side voltage, while GSC's controller injects voltage in order to retain the collector line's voltage at about the pre-fault value. In order for RSC to adjust rotor speed or DC voltage [22], $i_{r q}$ can be adjusted via $v_{r q}$, using (7) and (4). Maintaining a constant voltage at the stator winding terminal is carried out by $i_{r d}$ via $v_{r d}[23]$. The control diagram is shown in Figure 2(a), where control blocks including the rotor speed, DC voltage, rotor current and PI controls are used as in [22, 23]. In order for GSC to maintain a high enough voltage on the collector line, GSC should inject voltage into the collector line to compensate the error between pre-fault and actual value. The current in the collector line can occur with a negative component, and hence, GSC should reduce it. The control diagram for GSC is shown in Figure 2(b).

(a)

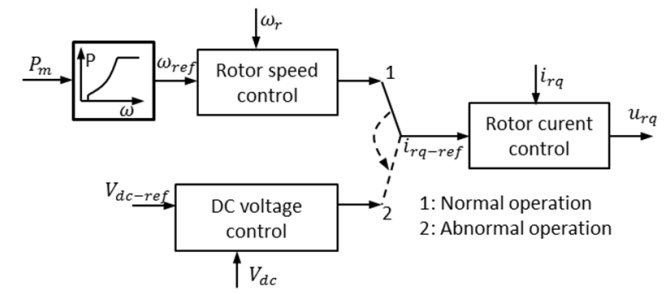

(b)

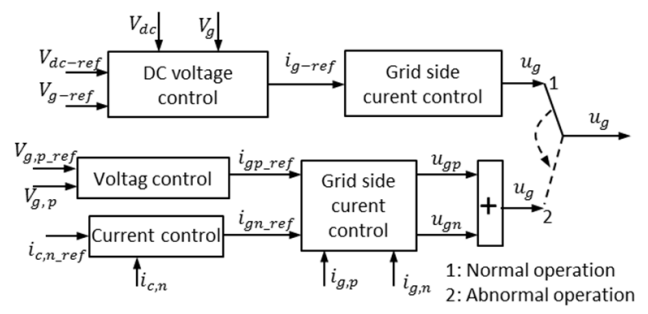

Fig. 2. Controller applying to the first wind turbine: (a) rotor side converter, (b) grid side converter
Reference values are determined by:

$$
\begin{gathered}
V_{g, p-r e f}=\sqrt{V_{\text {rated }}^{2}-\left\|v_{l d q, p}\right\|^{2}} \\
v_{l d q, p}=\left[\begin{array}{ll}
v_{l d, p} & v_{l q, p}
\end{array}\right]^{T} \\
V_{g d q, p-r e f}=\frac{V_{g, p-r e f}}{\left\|v_{l d q, p}\right\|} v_{l d q, p} \\
I_{c, n-r e f}=\left[\begin{array}{ll}
i_{c d, p-r e f} & i_{c q, p-r e f}
\end{array}\right]^{T}=0
\end{gathered}
$$

where $\boldsymbol{V}_{g, p-r e f}$ is the magnitude of the positive component of the GSC side voltage, $\boldsymbol{V}_{\text {rated }}$ is the rated voltage in the collector line referring to the GSC side voltage, $\left\|\boldsymbol{v}_{l d q, p}\right\|$ is the magnitude of the positive component voltage in the $d q$ frame of the connected line (or PCC), referring to the GSC side voltage, $\boldsymbol{V}_{g d q, p-r e f}$ is the reference voltage in the $d q$ frame of the positive component voltage, $\boldsymbol{i}_{c, n-r e f}$ is the reference negative component current in the $d q$ frame of the connected line, while $\boldsymbol{i}_{c, n}$ represents the actual negative component current in the $d q$ frame of the connected line. The more detailed control diagram applying to GSC of the first DFIG wind turbine is shown in Figure 3, where:

$$
\begin{gathered}
\boldsymbol{V}_{g d q, p}=\omega L_{f} \boldsymbol{\Phi} \boldsymbol{i}_{g d q, p}+\boldsymbol{v}_{g d q, p} \\
\Delta \boldsymbol{V}_{g d q, n}=-\omega L_{f} \boldsymbol{\Phi} i_{g d q, n}+\boldsymbol{v}_{g d q, n}
\end{gathered}
$$

$\theta_{l, p}$, and $\theta_{l, n}$ are phase angles for positive and negative component voltage, respectively.

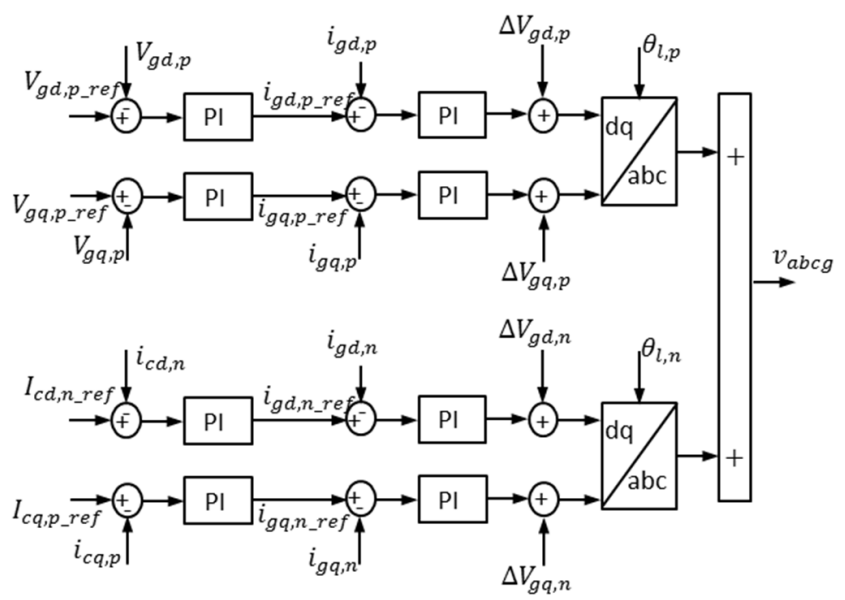

Fig. 3. Controller applied to the first wind turbine's grid side converter

\section{B. Other Wind turbines in the Group}

At normal operation, wind turbines are controlled to generate maximum power output and maintain a constant voltage at the stator winding terminal. However, when an external fault occurs, since the voltage at the collector line is retained at a high value by the first wind turbine, other wind turbines can generate high active power. This active power cannot be transferred to the connected grid, due to the low voltage on the connected line, so the wind turbine's controller objective of is to minimize the power output during the external fault. Therefore, RSC must control active power instead of the rotor speed as in normal operation, and GSC is controlled to 
receive all active power output in the stator side instead of DC voltage control. It is noted that RSC controller's reference power is set at minimum value.

(a)

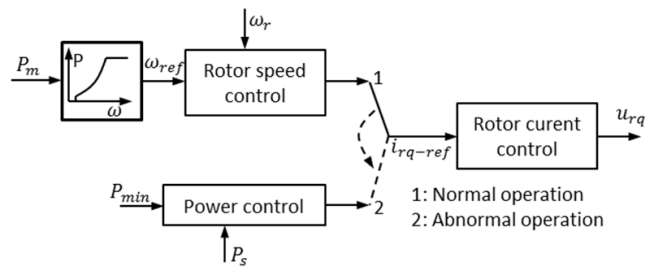

(b)

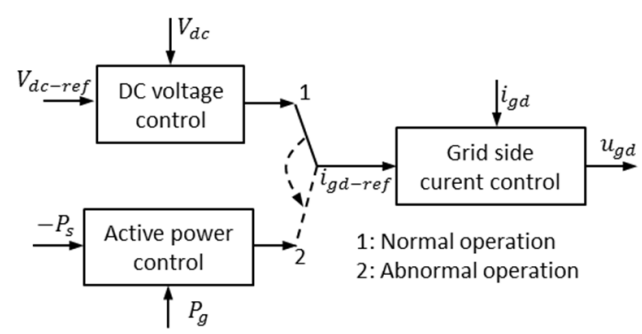

Fig. 4. Controller for the second to last wind turbine: (a) $q$ component of rotor side converter and (b) $d$ component of grid side converter

In order to control the rotor speed or the active power in the $d q$ frame, the $q$ component's rotor current must be adjusted via $v_{r q}$, as shown in Figure 4(a). It is possible to adjust the DC voltage on the DC link or the active power in the grid side converter, the $d$ component grid side current via $v_{g q}$, as in Figure 4(b). Here, PI control is used for rotor speed control, active power, rotor current, and grid side current control, as mentioned in $[24,25]$. Transferring from normal to abnormal operation mode is carried out when an external fault is detected.

\section{Chopper}

A chopper is installed in parallel with the DC-link at all wind turbines to dissipate all active power output generated by DFIG. A chopper and its controller are described in [26].

\section{VERIFICATION}

To verify the proposed model, MATLAB/Simulink was utilized to simulate a group of wind turbines with two methods, the proposed and the conventional. The conventional method which uses a crowbar at the rotor side and a chopper at the DC link of each generator is described in [26]. The parameters of a 1MW DFIG-wind turbine used in simulation are given in [27]. It is supposed that an external short-circuit occurs at $2 \mathrm{~s}$ and is cleared at $2.3 \mathrm{~s}$ on the feeder, as in Figure 1. Simulation results are shown in Figures 5 to 9. Figure 5 shows the voltage at the terminal of the wind turbines. As it can be seen from Figure $5(\mathrm{a})$, by using the proposed method the voltage on the stator winding terminal of all generators remains at around normal value during the external fault interval, while using the conventional method it is reduced to around $30 \mathrm{~V}$. Concerning the grid side's voltage of the first wind turbine, as shown in Figure 5(b), with the use of the proposed method quite significant fluctuations exist at the beginning and at the end of the external fault. On the other wind turbines, the grid side voltage is retained at the stator winding's terminal. Therefore using the proposed method, the voltage at the terminal of wind turbines is better than using the conventional method. Since the stator winding terminal voltage is reduced insignificantly at the beginning of the fault, the rotor current of all wind turbines at this time is smaller than the one obtained by using the conventional method, as shown in Figure 6. Therefore, using the proposed method, the overcurrent in the rotor side is mitigated significantly when the fault occurs.

(a)

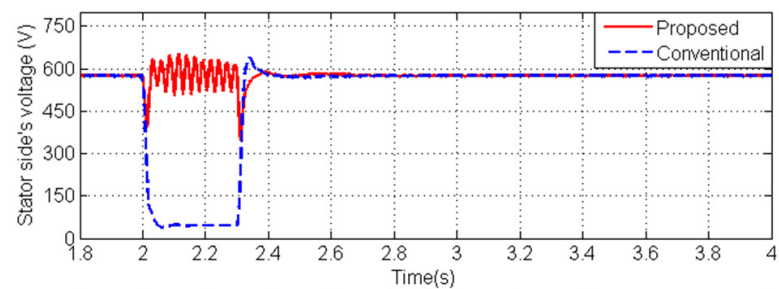

(b)

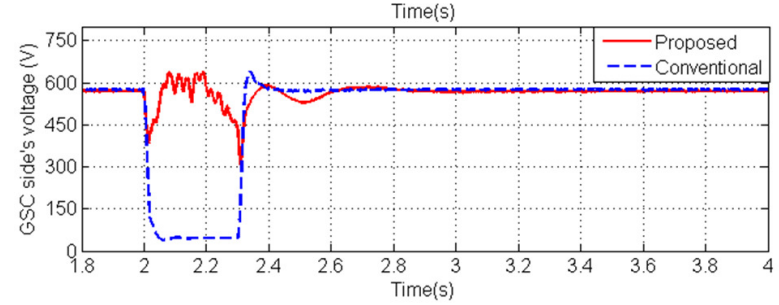

Fig. 5. Voltage at terminal wind turbine system: (a) stator side of generator and (b) grid side converter of the first wind turbine

(a)

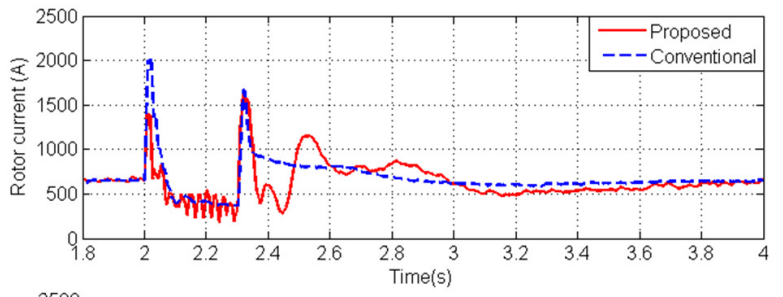

(b)

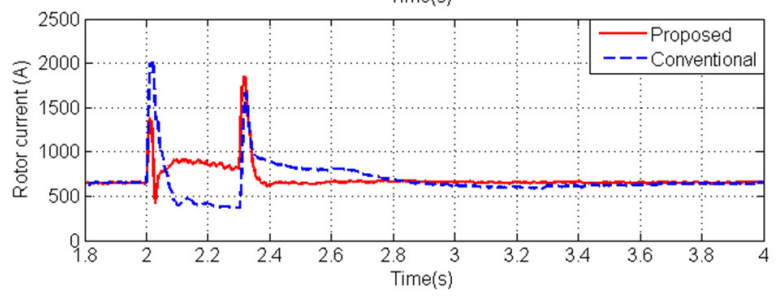

Fig. 6. Rotor current: (a) the first wind turbine and (b) other wind turbines

Normally, during an external fault interval, as wind power is almost constant and the active power cannot be distributed to the grid, the rotor speed increases. This can be seen in Figure 7 for both methods. However, using the proposed method, the voltage at both the stator and the grid side is retained at a high value and the active power generated by DFIG is dissipated on the chopper at the DC-link. Therefore, in the first wind turbine, the maximum value of the rotor speed during the fault interval is still smaller than using the conventional method, as shown in Figure 7(a). This benefit can be seen more clearly in the other wind turbines (Figure 7(b)). The rotor speed in these wind turbines when using the proposed method reaches only $1820 \mathrm{rpm}$ while using the conventional method reaches $1980 \mathrm{rpm}$. 
(a)

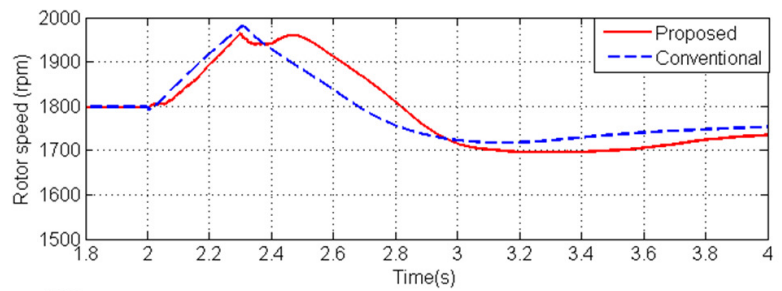

(b)

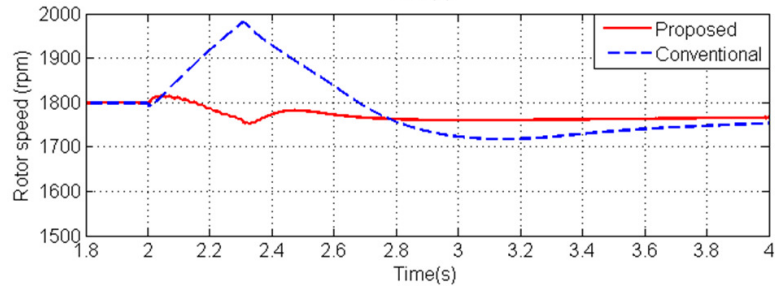

Fig. 7. Rotor speed: (a) the first wind turbine and (b) other wind turbines

As it can be seen from Figure 8 the active power supply to the grid is almost zero during the fault, in both methods, due to the low voltage on the connection line. However, in the conventional method the wind turbines still receive a small reactive power from the grid, while in the proposed method it is almost zero. When the external fault is cleared, after a short interval, wind turbines can supply stable power to the grid.

(a)

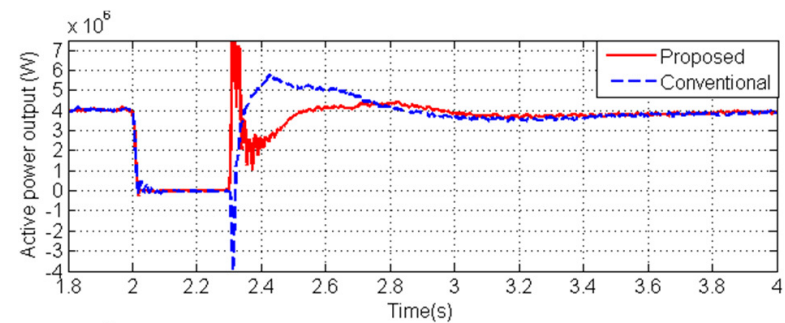

(b)

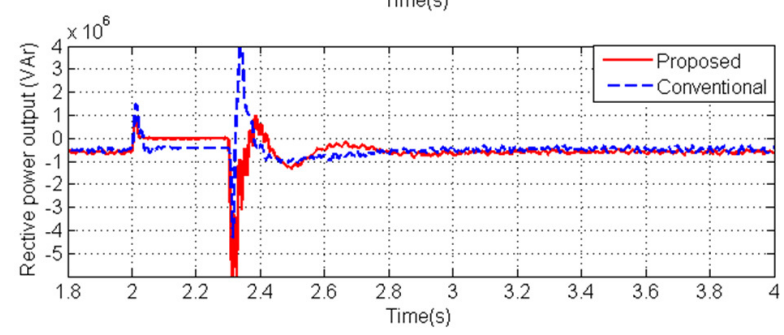

Fig. 8. Power output in total: (a) active power and (b) reactive power

\section{CONCLUSION}

In this research, the DC-link and the grid side converter of the first DFIG wind turbine in a wind turbine group is utilized to support the others in the case of an external fault. They are connected with a series transformer to inject voltage into the collector line. Each back-to-back converter of each DFIG wind turbine is equipped with a DC-chopper to dissipate the excessive active power during the fault period. Moreover, the controllers of wind turbines are modified to retain a minimal active power generation. Simulation results in MATLAB/Simulink indicated that by using the proposed method the wind turbine group has better performance than using the conventional method.

\section{ACKNOWLEDGMENT}

This work is supported by The University of Danang University of Science and Technology, code number of Project: T2019-02-47.

\section{REFERENCES}

[1] Global Wind Energy Council, Global Wind Report 2018, available at: https://gwec.net/wp-content/uploads/2019/04/GWEC-Global-WindReport-2018.pdf

[2] A. B. Lajimi, S. A. Gholamian, M. Shahabi, "Modeling and control of a DFIG-based wind turbine during a grid voltage drop", Engineering, Technology \& Applied Science Research, Vol. 1, No. 5, pp. 121-125, 2011

[3] O. P. Bharti, R. K. Saket, S. K. Nagar, "Controller design of DFIG based wind turbine by using evolutionary soft computational techniques", Engineering, Technology \& Applied Science Research, Vol. 7, No. 3, pp. 1732-1736, 2017

[4] V. F. Mendes, F. F. Matos, S. Y. Liu, A. F. Cupertino, H. A. Pereira, C. V. De Sousa, "Low voltage ride-through capability solutions for permanent magnet synchronous wind generators", Energies, Vol. 9, No. 1, Article ID 59, 2016

[5] M. Michas, C. E. Ugalde-Loo, N. Jenkins, "Grid code compliance and ancillary services provision from DFIG and FRC-based wind turbines", $51^{\text {st }}$ International Universities Power Engineering Conference (UPEC), Coimbra, Portugal, September 6-9, 2016

[6] H. Dong, H. Wu, J. Pan, Y. Chen, B. Xu, "Research on double-fed induction generator low voltage ride through based on double braking resistors using fuzzy control", Energies, Vol. 11, No. 5, Article ID 1155, 2018

[7] J. Vidal, G. Abad, J. Arza, S. Aurtenechea, "Single-phase DC crowbar topologies for low voltage ride through fulfillment of high-power doubly fed induction generator-based wind turbines", IEEE Transactions on Energy Conversion, Vol. 28, No. 3, pp. 768-781, 2013

[8] J. J. Justo, R. C. Bansal, "Parallel R-L configuration crowbar with series R-L circuit protection for LVRT strategy of DFIG under transient-state", Electric Power Systems Research, Vol. 154, pp. 299-310, 2018

[9] G. Pannell, B. Zahawi, D. J. Atkinson, P. Missailidis, "Evaluation of the performance of a DC-link brake chopper as a DFIG low-voltage faultride-through device", IEEE Transactions on Energy Conversion, Vol. 28, No. 3, pp. 535-542, 2013

[10] R. M. Monteiro Pereira, A. J. C. Pereira, C. M. Ferreira, F. P. M. Barbosa, "Influence of crowbar and chopper protection on DFIG during low voltage ride through", Energies, Vol. 11, No. 4, Article ID 885, 2018

[11] K. E. Okedu, S. M. Muyeen, R. Takahashi, J. Tamura, "Wind farms fault ride through using DFIG with new protection scheme", IEEE Transactions on Sustainable Energy, Vol. 3, No. 2, pp. 242-254, 2012

[12] L. Chen, C. Deng, F. Zheng, S. Li, Y. Liu, Y. Liao, "Fault ride-through capability enhancement of DFIG-based wind turbine with a fluxcoupling-type SFCL employed at different locations", IEEE Transactions on Applied Superconductivity, Vol. 25, No. 3, pp. 1-5, 2015

[13] M. Molinas, J. A. Suul, T. Undeland, "Low voltage ride through of wind farms with cage generators: STATCOM versus SVC", IEEE Transactionss on Power Electronics, Vol. 23, No. 3, pp. 1104-1117, 2008

[14] C. Wessels, F. Gebhardt, F. W. Fuchs, "Fault ride-through of a DFIG wind turbine using a dynamic voltage restorer during symmetrical and asymmetrical grid faults", IEEE Transactions on Power Electronics, Vol. 26, No. 3, pp. 807-815, 2011

[15] Y. Liao, H. Li, J. Yao, K. Zhuang, "Operation and control of a gridconnected DFIG-based wind turbine with series grid-side converter during network unbalance", Electric Power Systems Research, Vol. 81, No. 1, pp. 228-236, 2011

[16] P. H. Huang, M. S. El Moursi, W. Xiao, J. L. Kirtley, "Novel fault ridethrough configuration and transient management scheme for doubly fed 
induction generator”, IEEE Transactions on Energy Conversion, Vol. 28, No. 1, pp. 86-94, 2013

[17] O. P. Bharti, R. K. Saket, S. K. Nagar, "Controller design for DFIG driven by variable speed wind turbine using static output feedback technique", Engineering, Technology \& Applied Science Research, Vol. 6, No. 4, pp.1056-1061, 2016

[18] D. C. Phan, "Retaining of Frequency in micro-grid with wind turbine and diesel generator", Engineering, Technology \& Applied Science Research, Vol. 8, No. 6, pp.3646-3651, 2017

[19] H. Bassi, Y. A. Mobarak, "State-space modeling and performance analysis of variable-speed wind turbine based on a model predictive control approach", Engineering, Technology \& Applied Science Research, Vol. 7, No. 2, pp. 1436-1443, 2017

[20] D. C. Phan, S. Yamamoto, "Rotor speed control of doubly fed induction generator wind turbines using adaptive maximum power point tracking", Energy, Vol. 111, pp. 377-388, 2016

[21] D. C. Phan, S. Yamamoto, "Maximum energy output of a DFIG wind turbine using an improved MPPT-curve method", Energies, Vol. 8, No. 10, pp. 11718-11736, 2015

[22] G. D. Marques, M. F. lacchetti, "Sensorless frequency and voltage control in the stand-alone DFIG-DC system", IEEE Transactions on Industrial Electronics, Vol. 64, No. 3, pp. 1949-1957, 2017

[23] V. T. Phan, H. H. Lee, T. W. Chun, "An effective rotor current controller for unbalanced stand-alone DFIG systems in the rotor reference frame", Journal of Power Electronics, Vol. 10, No. 6, pp. 724-732, 2010

[24] R. Quan, W. Pan, “A low-order system frequency response model for DFIG distributed wind power generation systems based on small signal analysis", Energies, Vol. 10, No. 5, Article ID 657, 2017

[25] M. Zamanifar, B. Fani, M. E. H. Golshan, H. R. Karshenas, "Dynamic modeling and optimal control of DFIG wind energy systems using DFT and NSGA-II", Electric Power Systems Research, Vol. 108, pp. 50-58, 2014

[26] W. Li, P. Chao, X. Liang, Y. Sun, J. Qi, X. Chang, "Modeling of complete fault ride-through processes for DFIG-based wind turbines", Renewable Energy, Vol. 118, pp. 1001-1014, 2018

[27] B. Vu, Y. Lang, N. Zargari, S. Kouro, “Appendix B”, in: Power Conversion and Control of Wind Energy Systems, John Wiley \& Sons, New Jersey, 2011 